\title{
575
}

mächtige, aber zuweilen ansehnlich ausgedehnte und nutzbare Lager.

\section{Ueber die Fällung einiger Metalloxyde durch} Wasser; con Heinrich Rose.

In einer Abhandlung, welche ich vor kurzer Zeit bekanut machte ${ }^{1}$ ), verglich ich die Bildung des Aethers aus einem Gemenge von Schwefelsäure und Alkohol mit der Zersetzung mehrerer unorganischer Salze vermittelst des Wassers. Ich suchte es wabrscheinlich 24 machen, dafs es das Wasser ist, welches in diesen Fallen als Base auftritt, und das Aethyloxyd oder das Metalloxyd, letzteres gewöhnlich als basisches Salz, abscheidet.

Die unorganischen Salze, welche ich bei dieser Vergleichung als Beispiele anführte, sind die des Wismuthoxyds, des Quecksilberoxyds und des Antimonoxyds. Diese erleiden die erwähnte Zersetzung durch Wasser schon bei der gewöhnlichen Temperalur. Der Aether wird indessen erst bei erböbter Temperatur aus einem Gemenge von Schwefelsäiure und Alkohol oder aus der Schwefelweinsăure abgeschieden.

Es giebt indessen unter den unorganischen schwächeren Basen eine nicht unbeträchtliche Anzahl, welche aus ibren Verbindungen unit Săuren durch Wasser erst bei erböhter Temperatur abgeschieden werden; und die Zersetzung der Salze dieser Basen vermittelst des Wassers ist daher noch zweckmälsiger mit der Bildung des Aethers zu vergleichen.

Zu diesen Basen gehört besonders das Eisenoxyd, das aus den duflősungen der meisten seiner neutralen Salze durch Wasser bei erhobter Temperatur als ein

1) Poggendorf?'s Annalen, d. B. S. 453. 


\section{6}

basisches Salz gefält wird. Je verdünnter die Auflüsung des Eisenoxydsalzes ist, um so niedriger braucht die Temperatur bei der Fallung zu scyn, und un so vollständiger wird das Eisenoxyd gefillt, so dals bei einer gewissen Verdünuung, wie Scheerer ${ }^{1}$ ) gezeigt hat, fast gar kein Eisenoxyd in der Auflüsung bleibt, sondern die ganze Masse desselben als basisches Salz sich abscheidet. - Da stärkere Basen durch Wasser auch beim Kochen nicht gefällt werden, so bat wan sich dieser Eigenschaft des Eisenoxyds bedient, um dasselbe von den Oxyden des Kobalts, des Nickels und anderer Metalle zu trennen ${ }^{2}$ ). Auch selbst von der Thonerde, die, obgleich sie hinsichllich ihrer Eigenschaften viele Achnlichkeit mit dem Eisenoxyde hat, aber offenbar eine stärkere Base als dieses ist, kann letztcres durch Kochen der Auflosung getrennt werden, und diese Trennung der Thonerde und des Eisenoxyds verunittelst des Wassers bei erböbter Temperatur ist in technischer Hinsicht von gewisser Wichtigkeit, weil bei der Fabrication des Alauns nur durch Kochen das in der Lauge enthaltene Eisenoxyd gefillt wird, und dadurch leichter von der Thonerde zu trennen ist, als das aus diesem Grunde weit nachtheiligere Eisenoxydul, obgleich das Eisenoxyd mit Schwefelsăure und Alkali einen Alaun bildet, der ganz dem Thonerdealaun analog zusammengesetzt, und, weil er auch mit diesem isomorph ist, mit ihm deshalb in allen Verhältnissen zusammenkrystallisiren könntc.

Wie das Eisenoxyd verhalten sich mehrere anderc Basen, welche indessen alle, wie jenes, zu den schwachen gehören, so wie nuch mehrere Substanzen, die gegen starke Süuren wie Basen, gegen starke Basen aber vie Säuren reagiren, und deshalb häufig zu den Säuren gezählt werden. Es gehören hierzu die Zirconerde, die

'lhor-

1) Poggen dorff's Annalen, Bıl. XXXXIV S. 453.

2) Schecer in Poggendorff's Annalen, Bd. XXXXII S. 104. 
Thorerde, das Ceroxyd, das Zinnoxyd, die Titansäure, die Tantalsăure, die tellurichte Säure, auch in gewisser Hinsicht die Molybdänsäure, die Wolframsäure und die Vanadinsäure. Mehrere Verbindungen dieser Oxyde mit Säuren können sich in kalten Wasser auflösen, und werden aus der Auflossung durch's Kochen als Oxyde oder als basische Salze gefält.

Mehrere von den auf diese Weise gefältten Oxyden besitzen nach der Fällung durch's Kochen Eigenschaften, die sie vor der Auflüsung in Säuren und Fällung aus denselben nicht zeigten. Sie verhalten sich indifferenter als zuvor, sind in Säuren theils schwerlüslich, theils unluslich geworden, und verbinden sich nach der Fällung nicbt unmittelbar mit ihnen, selbst wenn diese auch im concentrirten Zustand angewandt werden. Man kann zu diesen die Titansüure, das Zinnoxyd und mehrere andere rechnen. Dieses Verhalten ist gewissermafsen dein des Aethers analog, der, wenn er durch's Kochen aus einem, Schwefelw einsüure entbaltenden, Gemenge ausgesclieden worden ist, sich nicht unmittelbar mit Säuren zu Salzen zu verbinden scheint.

VII. Ueber die Zusammensetzung des Eläoliths; von C. Bromeis.

In dem 46sten Bande dieser Annalen, S. 291, befindet sich eine neue Untersuchung über die chemische Zusammeusetzung des zu Brevig, in südlicben Norwegen, vorkommenden Eläoliths von Hrn. Scheerer, durch welche sich dieser Chemiker veranlafst sieht, die bisher für den Eläolith angenommene Formel $\left(\dot{\mathrm{K}}^{3}, \dot{\mathrm{N}} \mathrm{a}^{3}\right) \dddot{\mathrm{S}} \mathrm{i}+3 \dddot{\mathrm{Al}} \dddot{\mathrm{S}} \mathrm{i}$ zu verwerfen, und eine neue, näılich $\left(\dot{K}^{2}, \dot{N_{a}}{ }^{2}\right) \ddot{S}+2 \dddot{A} i \dddot{S}$, dafür aufzustellen. Da indefs diese Formel an Einfach-

PosgendorfT's $\Lambda$ nnal. Bd. XXXXVIII. 